\title{
An approach for cost and configuration optimization of horizontal axis wind turbine (HAWT)
}

\author{
I. Elbahnasy ${ }^{1}$ and K. Ellermann ${ }^{2}$ \\ ${ }^{1}$ Graz University of Technology \\ Graz, Austria \\ Mailing address: Institut für Mechanik, $8010 \mathrm{Graz}$, Kopernikusgasse 24/IV \\ Phone/Fax number: 0045 30376857, e-mail: ibahnasy1@yahoo.com \\ ${ }^{2}$ Graz University of Technology, Institute of Mechanics \\ Mailing address: Institut für Mechanik, $8010 \mathrm{Graz}$, Kopernikusgasse 24/IV \\ Phone/Fax number: 0043 (316) 873 - 7140, email: ellermann@tugraz.at
}

\begin{abstract}
In addition to the environmental advantage of wind turbines, the modern wind turbine design is aiming to become more competitive by minimizing the cost of energy (COE). When evaluating any change to the design of a wind turbine, it is critical that the designer evaluates the impact of the design change on the system cost and performance. A typical problem when start a wind turbine design project is to determine the optimum configuration and operation parameters to minimize COE.
\end{abstract}

In this article an optimization approach is adopted using COE as objective function with the rotor size, power rating and rated rotational velocity (RPM) as design variable. The cost of energy model of the National Renewable Energy Laboratory (NREL) is adopted with modifications to include the main components load level effects on the COE.

An aerodynamic blade design is developed and used as base for evaluating the rotor performance. The blade is scaled to present different rotor size and operating conditions for each power rating. Analysis tool is developed to consider coupled interactions between power rating and the rotor size. The Blade Element Momentum (BEM) technique is used to evaluate the effect of configuration and operational conditions on the wind turbine load levels and the expected annual energy production (AEP). These are used as inputs for the proposed COE model in addition to main parameters presenting the manufacturing technology and site conditions.

The COE model is based on several elements such initial capital cost (ICC), balance of station (BOS), operations and maintenance $(\mathrm{O} \& \mathrm{M})$, levelized replacement cost (LRC), AEP and design load levels. A pattern search technique is adopted for the optimization and the approach is illustrated by means of a principle test examples for two types of turbines platform one for low wind onshore site and another for high wind offshore site.

\section{Key words}

Wind turbine, Cost of energy, Optimization, Design, Power rating, Rotor size, rated rotational speed.

\section{Introduction}

During the preliminary design of a wind turbine, the question is raised about what shall be the best design. The term optimum design is widely used expression which can go from overall system level down to each minor component in subassembly. In this article an approach is presented to determine the optimum wind turbine configuration taking $\mathrm{COE}$ as objective of the optimization.

The NREL has developed a cost model based on market survey and financial data in addition to the expectation of the turbine size for the planned wind turbine [1]. That model was recursively updated and the latest update was presented in 2013 [2]. There were some trials to define an approach to optimize the wind turbine design [3] but it was mainly dedicated to the rotor with intensive investigation to the rotor performance and aero- elastic modelling of the blade without considering the rest of turbine components.

The consideration of the turbine components, and the load level of each component and the effect on the cost was considered in [4] but it was limited to two wind turbine configurations $1.5 \mathrm{MW}$ and $2 \mathrm{MW}$ while keeping the blade size fixed and changing the rotor size by increasing the hub radius. A simpler technique was adopted in [5] to find the optimum rotor to generator size with simple cost model for only generator and rotor with fixed total cost without considering the wind turbine operation parameters and its effect on the cost.

The approach presented in this article is aiming to present a generic approach to optimize the wind turbine design through cost of energy as objective. The approach is aiming also to increase fidelity to the results by incorporating complex cost model and considering both 
load level on the main components and wind turbine operational parameters into the cost model. This information is vital during the preliminary design of wind turbine platform which gives a guide to the intended cost of the turbine and also to the design driving parameters.

\section{Description of the Approach}

The approach is based on developing a design tool which combines numerical optimization algorithm with different basic calculation tool through an interface.

The input to the problem is divided into the information which is required to execute the numerical optimization algorithm and the specifications for the basic calculation tools.

\section{A. The optimization algorithm}

The numerical optimization algorithm needs the following:

1) An objective function: The cost of energy that has to be minimized by changing the design variables.

2) A set of design variables: Parameter that influences cost of energy such as rotor size.

3) Constraints: Upper or lower values for the design variables and any calculable response parameter that is dependent on the design variables. The constraints bound the design space into a feasible domain in which the optimum is found. Boundaries to the operation of the turbine such as tip speed limits due to noise level.

4) Finally, an initial guess on a design vector is needed.

B. The specifications for basic calculation tools.

The specifications of the basic calculation tool include the wind climate that is specified as the incoming mean velocity profile, density and shear profile.

When the design tool is applied, different basic calculation tools are used:

1) Traditional aerodynamic analysis based on blade element/momentum theory is used for calculation of the power.

2) Extreme loads are determined from outputs of the aerodynamic analysis tool.

3) Weibull distributions is adopted in estimating AEP

4) COE calculation model based on several elements such initial capital cost (ICC), balance of station (BOS), operations and maintenance $(O \& M)$, levelized replacement cost (LRC), AEP and design load levels.

The execution of the different calculation tools is controlled by the interface that is tailored for communication between the numerical optimization algorithm and the calculation models.

It generates the wind turbine configuration from the design variables. When the calculation tools have been executed, the interface evaluates the objective function and the constraints.

\section{Design variables}

The design variables are chosen based on the ability to be modelled in the BEM technique in addition to represent geometrical, aerodynamically and operational characteristic of the wind turbine.

From above the following design variables are chosen
1) Generator power rating
2) Rotor radius,
3) Rated rpm,

which are found to be representative to the turbine configuration and operation during the preliminary design phase of the wind turbine.

In addition to the BEM outputs of power performance [6], [7], steady load level could be presented as in eqs. (1), (2), and (3).

$$
\begin{array}{r}
M=f_{1}\left(\Omega, R, P, C_{p}, V_{w}, \ldots\right) \\
T=f_{2}\left(\Omega, R, P, . C_{p}, V_{w}, \ldots\right) \\
Q=f_{3}\left(\Omega, R, P, C_{p}, V_{w}, \ldots\right)
\end{array}
$$

Where

$\mathrm{M}=$ blade flap moment

$\mathrm{T}=$ rotor thrust

$\mathrm{Q}=$ rotor torque

$\Omega, R, P, C_{p}, V_{w}=$ rotor $\mathrm{rpm}$, rotor radius, power, power coefficient and wind speed respectively.

\section{A. Changing the rotor size}

The choice of rotor radius as design variables leads to the question about the methodology to change the rotor radius.

In this article, a scaling methodology is adopted to change the rotor size. The scaling is done by using reference blade design which is scaled to represent the change in the rotor size. The scaling is uniform to increase the rotor radius without violating the aerodynamic characteristics of each aerofoil on the blade.

Two aerodynamics pre-designed blades are used for the scaling. Each of them is dedicated to power rating range of the wind turbine as follows:

1) Blade design 1: 40 m blade for low to mid power turbines(1.0-2.5 MW) and wind class IECIII ( mean wind speed $=7.5 \mathrm{~m} / \mathrm{s}$ )

2) Blade design 2: $65 \mathrm{~m}$ blade for mid to high power turbines(5.0-8.0 MW) and wind class IECI (mean wind speed $=10 \mathrm{~m} / \mathrm{s}$ ) 
The aerodynamic designs of the blades are based on optimizing the aerodynamic efficiency of the blade and the overall performance of the blade to maximize the AEP as in [6], [7]. The airfoils used for the aerodynamic design of the blades are
1) Riso airfoils [8].
2) Delft airfoils [9].
3) NACA airfoils[10].

\section{B. Changing the rated power}

Changing the rated power will lead to changing in the BEM model outputs and also to modify the power loss model due to the effect of the increasing the torque and rated rpm.

The loss model incorporated in this article is the same loss model incorporated in [11] and [12] which could be presented as in (4).

$$
P_{\text {loss }}=f_{4}(P, Q, \Omega)
$$

\section{Cost model}

The formulation in eq. (1) to eq. (3) for loads could be related to the main components cost as follows:

$$
\begin{aligned}
T C & =f_{5}(T, M, H, \ldots) \\
B C & =f_{6}(M, Q, \ldots) \\
H C & =f_{7}(Q, T, \ldots) \\
R C & =f_{8}(H C, B C, \ldots)
\end{aligned}
$$

$$
\begin{gathered}
D T C=f_{9}(Q, P, R, \Omega, \ldots) \\
F C=f_{10}(T C, T, R, \Omega, \ldots) \\
N A C=f_{11}(P, R, \Omega, \ldots)
\end{gathered}
$$

Where

$\mathrm{TC}=$ tower cost, $\mathrm{H}=$ hub height, $\mathrm{BC}=$ blade cost, $\mathrm{HC}=$ hub cost, $\mathrm{RC}=$ rotor cost, $\mathrm{DTC}=$ drive train cost, $\mathrm{FC}=$ foundation cost and $\mathrm{NAC}=$ nacelle cost .

The other parameters defining the detail cost such as maintenance, operational and installation costs are based on the empirical formulation from NREL cost model [1] and [2].

The cost model of the offshore turbine is different from the onshore model in two main aspects. The first aspect concerning the components cost is the foundation, which is by far more complicated and expensive.

The second aspect is due to the more sophisticated cost estimation for the installation, maintenance and operation as it has a dominant effect on the COE.

\section{The Design Tool}

In order to test the approach, a MATLAB code was developed in this work. The pattern search technique is adopted for optimization. A flow chart of the developed tool is shown in Fig. 1 and a snapshot of the tool input window is shown in Fig. 2.

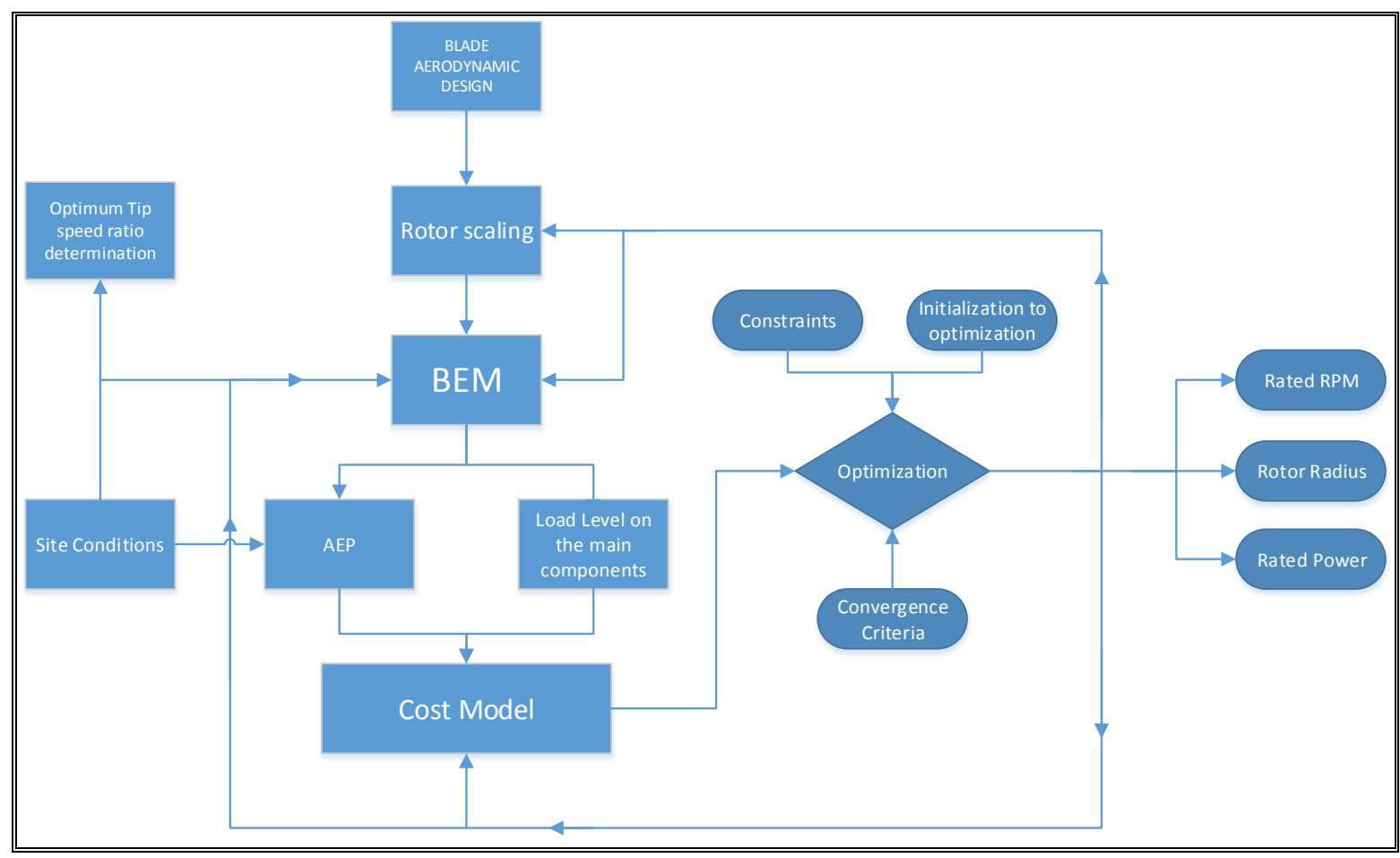

Fig.1. Cost and design optimization tool flowchart. 


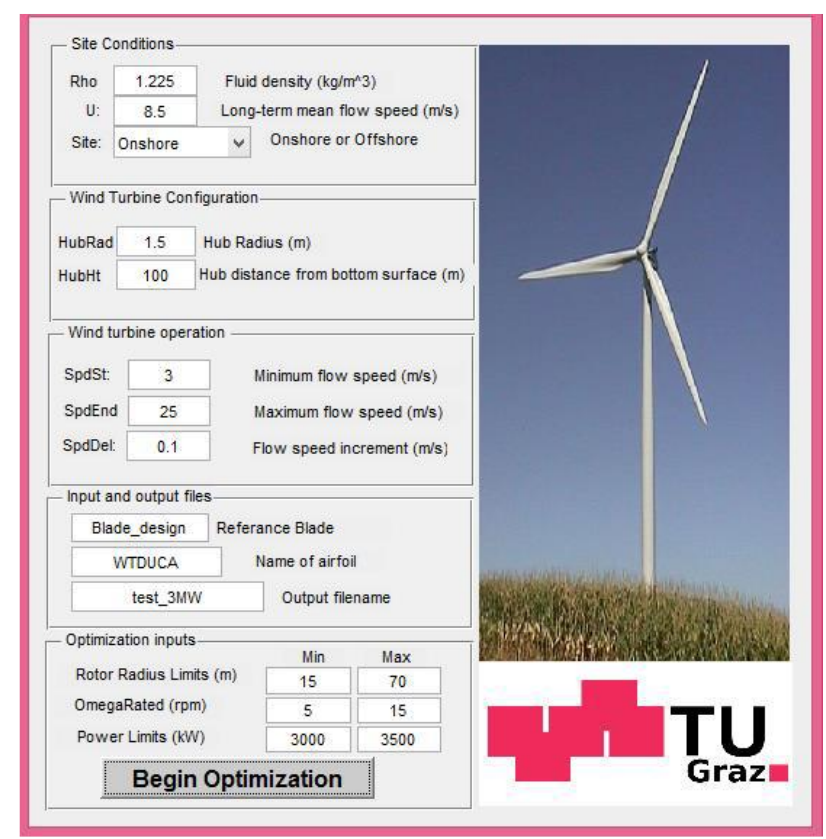

Fig.2. Snapshot from the wind turbine optimization tool

The outputs of the optimization tool are as follows:

1) Breakdown cost report of the wind turbine

2) Extreme load levels on the main components

3) The COE value

4) The optimized design variable values

5) The aerodynamic design of the blade corresponding to the optimum rotor size

6) Performance charts corresponding to the optimum design (power curve, power coefficients, thrust ...etc.).

\section{Test Examples}

Two test examples are used to test the approach. The two test examples are based on variable- speed pitch-regulated wind turbine.

The choice of the test examples are based on representing both low and high wind sites in addition to cover both offshore and onshore sites.

The characteristics of each of them are listed in the following tables:

Table I. - first test example characteristics and constraints

\begin{tabular}{|l|c|}
\hline Site type & onshore \\
\hline Site density & $1.225 \mathrm{~kg} / \mathrm{m} 3$ \\
\hline Annual average wind speed & $7.5 \mathrm{~m} / \mathrm{s}$ \\
\hline Hub-height & $90 \mathrm{~m}$ \\
\hline Cut in wind speed & $3 \mathrm{~m} / \mathrm{s}$ \\
\hline Cut out wind speed & $25 \mathrm{~m} / \mathrm{s}$ \\
\hline Rotor radius range & $30-70 \mathrm{~m}$ \\
\hline Power rating range & $1 \mathrm{MW}-2.5 \mathrm{MW}$ \\
\hline Rated rpm range & $10-25$ \\
\hline
\end{tabular}
cost and COE are shown in Table III.

Table III.-first test example summarized cost report

\begin{tabular}{||r|r||}
\hline \multicolumn{2}{|l|}{ MAIN CONFIGURATION OF THE TURBINE } \\
\hline \hline Machine Rating (kW) & $1,368.29$ \\
Rotor Diameter (m) & 92.02 \\
Hub Height (m) & 90.00 \\
OMEGA (rad/s) & 1.60 \\
CAPACITY FACTOR & 0.47 \\
\hline \hline COMPONENT & TOTAL CoST \$ \\
\hline \hline ROTOR & $350,755.63$ \\
DRIVE TRAIN, NACELLE & $663,167.98$ \\
CONTROL, SAFETY SYSTEM, CONDITION MONITORING & $53,363.12$ \\
TOWER & $264,632.35$ \\
TURBINE CAPITAL COST (TCC) & $1,367,751.89$ \\
BALANCE OF STATION COST (BOS) & $531,829.25$ \\
INITIAL CAPITAL COST (ICC=BOS+TCC) & $1,899,581.14$ \\
Levelized Replacement Cost(LRC) & $19,032.85$ \\
Operations \& Maintenance & $51,414.72$ \\
Land Lease Costs (LLC) & $7,932.56$ \\
AEP (Kwh) & $5,649,969.69$ \\
FIXED CHARGE RATE (FCR)=9,5\% & $180,460.21$ \\
\hline \hline & 0.0458127 \\
\hline
\end{tabular}

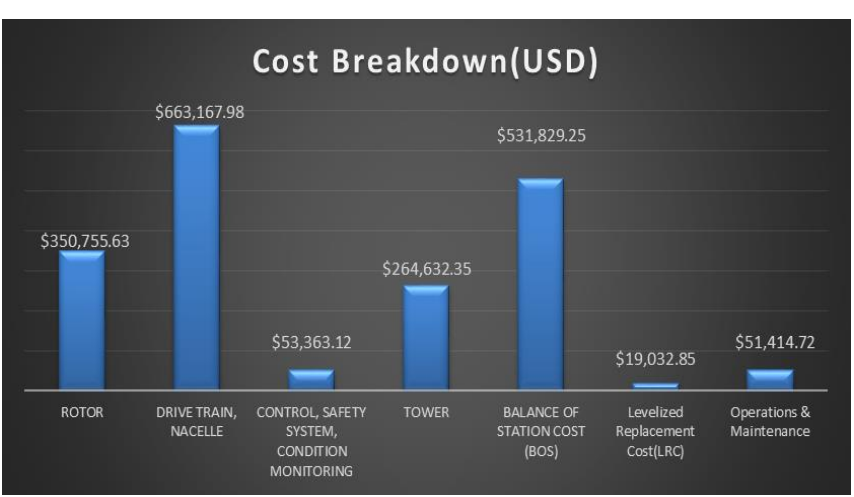

Fig.3. first test example cost break down

\begin{tabular}{|l|c|}
\hline Site type & offshore \\
\hline Site density & $1.225 \mathrm{~kg} / \mathrm{m} 3$ \\
\hline Annual average wind speed & $10 \mathrm{~m} / \mathrm{s}$ \\
\hline Hub-height & $120 \mathrm{~m}$ \\
\hline Cut in wind speed & $3 \mathrm{~m} / \mathrm{s}$ \\
\hline Cut out wind speed & $25 \mathrm{~m} / \mathrm{s}$ \\
\hline Rotor radius range & $50-95 \mathrm{~m}$ \\
\hline Power rating range & $5 \mathrm{MW}-8 \mathrm{MW}$ \\
\hline Rated rpm range & $7-16$ \\
\hline
\end{tabular}

\section{Results}

The results are presented as cost break down, cost report and power curve for both test examples.

\section{A. First test example results}

The first test example is an onshore turbine constructed configuration, components 


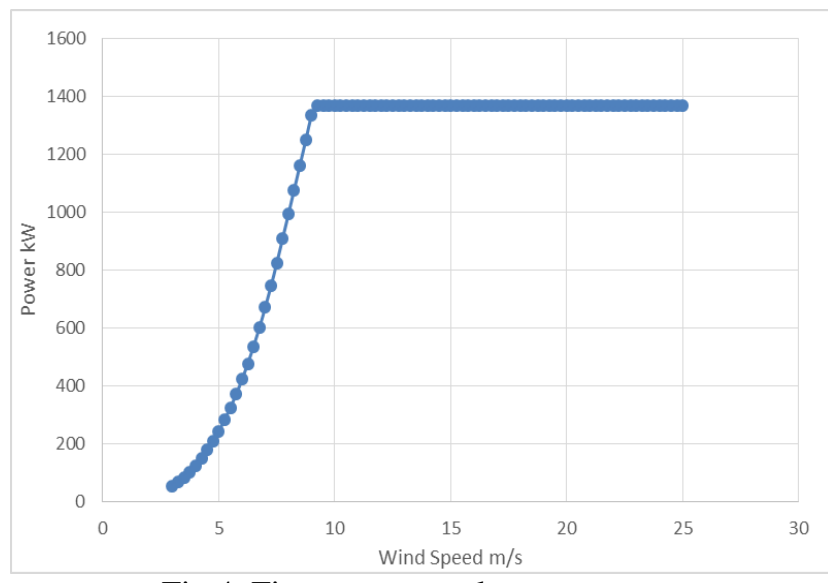

Fig.4. First text example power curve

The drive train and nacelle account for almost $35 \%$ of the turbine. A second important contribution results from the balance of station (BOS) cost, which is the summation of foundation, erection, transport and installation costs. The BOS represents almost $30 \%$.

From the above we can also interpret that in order to reduce the COE for onshore low wind sites, the rotor size shall be increased even for low rated power.

\section{B. Second test example results}

The second test example is given by an offshore turbine constructed for high wind sites. The main configuration, component cost report and COE are given in Table IV.

Table IV.-Second test example summarized cost report

\begin{tabular}{||r|r|}
\hline \multicolumn{2}{|c|}{ MAIN CONFIGURATION OF THE TURBINE } \\
\hline \hline Machine Rating (kW) & $5,000.00$ \\
Rotor Diameter (m) & 145.59 \\
Hub Height (m) & 100.00 \\
OMEGA (rad/s) & 1.08 \\
CAPACITY FACTOR & 0.55 \\
\hline \hline COMPONENT & TOTAL COST \$ \\
\hline \hline ROTOR & $1,402,130.30$ \\
DRIVE TRAIN, NACELLE & $2,397,476.29$ \\
CONTROL, SAFETY SYSTEM, CONDITION MONITORING & $195,000.00$ \\
TOWER & $852,680.13$ \\
MARINIZATION & $850,698.82$ \\
TURBINE CAPITAL COST (TCC) & $5,878,947.40$ \\
BALANCE OF STATION COST (BOS) & $5,473,368.74$ \\
OFFSHORE WARRANTY PREMIUM & $754,237.29$ \\
INITIAL CAPITAL COST (ICC=BOS+TCC) & $12,106,553.43$ \\
Levelized Replacement Cost(LRC) & $107,910.16$ \\
Operations \& Maintenance & $466,931.91$ \\
Land Lease Costs (LLC) & $33,565.31$ \\
AEP (Kwh) & $23,906,913.86$ \\
FIXED CHARGE RATE (FCR)= 11,58\% & $1,401,938.89$ \\
\hline \hline & 0.0840906 \\
\hline
\end{tabular}

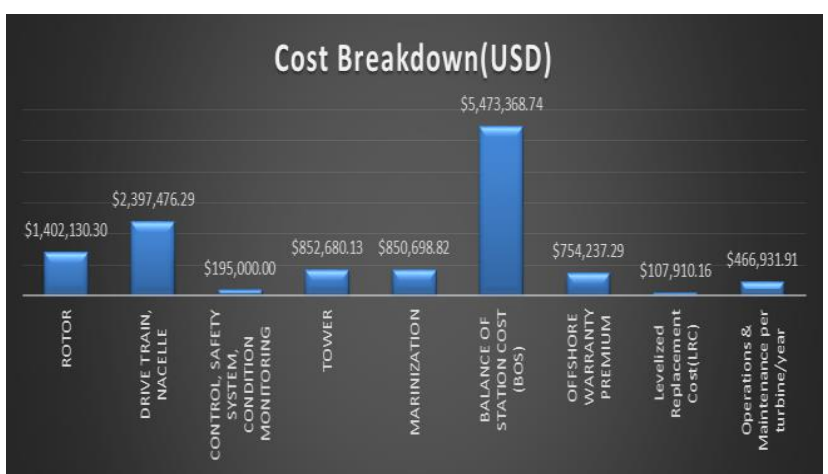

Fig.5. Second test example cost break down

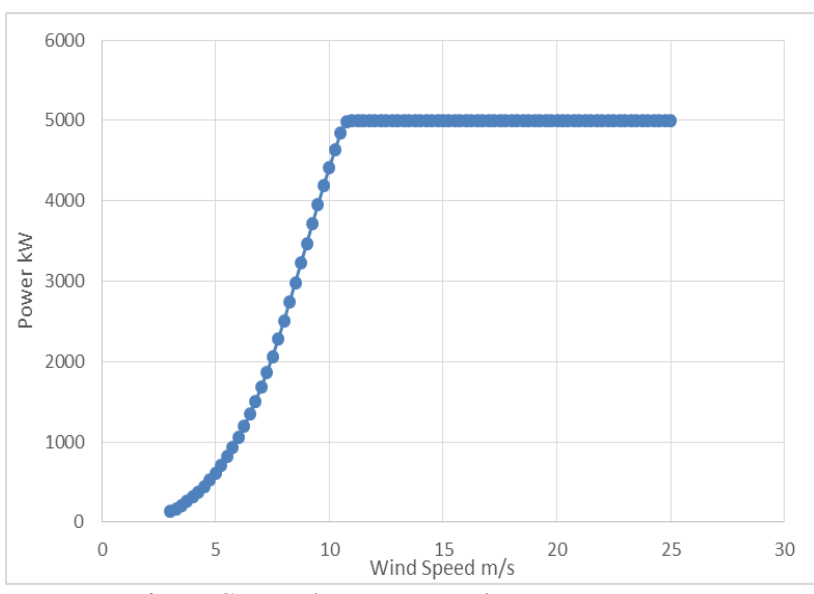

Fig.6. Second text example power curve

For this case, the drive train and nacelle account for almost $25 \%$ of the turbine while the balance of station cost represents almost $45 \%$. Here, the main cost driver is the nacelle cost and BOS (Balance of Stations) cost.

The examples indicate that increasing the rotor size is not the key driver of COE for high wind offshore sites, but the drive train cost with consideration to BOS cost play the major roles in offshore COE.

\section{Future work}

This article has shown that, there are still potential to develop and expand the approach with the following items:

A. Sensitivity analysis showing the effect of each design variable on $C O E$

B. Investigation of the effect of changing the reference blade aerodynamic design on COE

C. Include the drive train type a s design variable and investigate its effect on the COE

D. Expend the approach to investigate the wind farm $C O E$

E. Update the COE model with latest wind energy cost report and more focus on market specific cost. 


\section{Conclusion}

In this article an approach has been presented to optimize the cost of energy by utilizing cost of energy as objective function. The approach has utilized the complex cost model in addition to account for load level effect on cost.

Operational condition of the turbine represented by the rated rpm has been incorporated into the approach. The approach can be used for both onshore and offshore wind turbines.

The approach can give initial estimate of the COE for newly developed wind turbine without going into details of the sub components specification or design. The cost model can easily be changed and adopted to the changes based on the updated market price, financial inputs, labour hour cost, markets of interests, etc.

The optimum balance between generator power rating, rotor size and rated $\mathrm{rpm}$ to optimize $\mathrm{COE}$ is determined. The approach can present the aerodynamic performance for the optimized turbine configuration.

The approach has shown that, increasing the rotor size with reducing the rated power will reduce $\mathrm{COE}$ for onshore turbines at low wind site.

The BOS cost is the dominant parameter for offshore turbines. The approach has shown that, the offshore COE is almost double the COE of onshore turbines.

\section{References}

[1] L. Fingersh, M. Hand, and A. Laxson, "Wind Turbine Design Cost and Scaling Model", NREL/TP-500-40566, December 2006,

[2] S. Tegen, E. Lantz, M. Hand, B. Maples, A. Smith, and P. Schwabe, "2011 Cost of Wind Energy Review", NREL Technical report NREL/TP-5000-56266, March 2013.

[3] M. Døssing, "Optimization of wind turbine rotors - using advanced aerodynamic and aeroelastic models and numerical optimization", Risø-PhD-69(EN), May 2011

[4] K. Thomson, P. Fuglsang and G. Schepers, "Potential for site-specific design of MW sized wind turbine", AIAA-20010049.

[5] K. Martin, "Site specific optimization of rotor and generator sizing of wind turbines", Georgia Institute of Technology, December 2006.

[6] Hansen O.L Martin Wind Turbine Aerodynamics, James and james science publisher, 2008.

[7] Kulunk, E., Yilmaz, N., HAWT Rotor Design and Performance Analysis. ASME 3rd International Conference on Energy Sustainability, ES2009-90441. San Francisco, CA, USA. July19-23, 2009.

[8] Bertagnolio, F., Niels Sorensen, N., Johansen, J., Fuglsang, P. Wind Turbine Airfoil Catalogue. Riso National Laboratory, Roskilde, 2001.

[9] W.A. Timmer and R.P.J.O.M. van Rooij, Summary of the Delft University Wind Turbine Dedicated Airfoils, AIAA2003-0352.

[10] Abbott, Ira. Theory of Wing Sections: Including a Summary of Airfoil Data. New York: Dover Publication, (1959).

[11] Hau, E., Wind Turbines: Fundamentals, Technologies,
Application, Economics. Krailling, Springer, 2006.

[12] Burton, T. and Sharpe, D., Wind Energy Handbook. John Wiley and Sons Ltd, ISBN 0-471-48997-2, Chichester, 2006. 